\title{
O Manifesto Comunista, 170 anos mais tarde 1
}

\author{
The Communist Manifesto, 170 years later
}

\section{Samir AMIN*}

1. $\mathrm{N}$ enhum texto escrito em meados do século XIX se mantém tão atual hoje em dia quanto o Manifesto Comunista de 1848. Lidas atualmente, frases inteiras do texto correspondem à realidade contemporânea, ainda melhor do que em 1848. Partindo de premissas ainda latentes na época, Marx e Engels tiram conclusões que o desenrolar de 170 anos de história iria confirmar plenamente. Mais à frente deste artigo citarei exemplos contundentes.

Marx e Engels eram profetas inspirados? Mágicos capazes de ver em uma bola de cristal? Seres excepcionais por conta de suas intuições? Não. Tinham apenas compreendido, melhor do que qualquer outro, tanto na época deles quanto em nossa época, a essência do que define e caracteriza o capitalismo. Marx consagrou toda a sua vida para aprofundar essa análise por meio do exame do duplo sentido da nova economia (a partir do exemplo da Inglaterra) e da nova política (a partir do exemplo da França).

Escrevi sobre esse tema no Le centenaire de la Révolution d'Octobre $1917^{2}$, capítulo três de Ler o Capital, ler os capitalismos históricos :

A obra maior de Marx - O Capital - nos propõe uma análise científica rigorosa sobre o que o modo de produção e a sociedade capitalista são, em contraposição ao que eram as sociedades anteriores. O livro I nos coloca no seio do problema. Ele nos esclarece de imediato o que significa a generalização da troca mercantil entre proprietários privados (e essa característica é própria do mundo moderno do capitalismo, mesmo que as trocas mercantis já tivessem existido anteriormente): a emergência e o domínio do valor e do trabalho social abstrato. A partir daí, Marx nos permite compreender como a venda pelo proletário de sua força de trabalho ao homem endinheirado assegura a produção de um mais-valor apropriado pelo capitalista que, por sua vez, constitui a condição para a acumulação do capital. Esse domínio do valor não comanda apenas a reprodução do sistema econômico do capitalismo: ele comanda todos os aspectos da vida social e política moderna. Desse modo, a alienação mercantil permite compreender o mecanismo ideológico pelo qual se impõe a coerência do conjunto da reprodução social (AMIN, 2017a).

O instrumento intelectual e político, qualificado posteriormente de marxismo, revelou-se a melhor forma de prever, de maneira correta, a evolução histórica da realidade capitalista, em

${ }^{1}$ Texto traduzido do original em francês para o português pelo Prof. Luiz Jorge V. P. de Mendonça.

* Economista. Doutor em Economia. Nota dos editores: Em 21/3/2018 recebemos este artigo para ser publicado na seção Debate. Em 12/8/2018 fomos com pesar comunicados do falecimento do Prof. Samir Amin.

${ }^{2}$ O centenário da revolução de outubro de 1917. 
linhas gerais. Nenhuma das tentativas de pensar fora do marxismo - e frequentemente contra ele - chegou a resultados comparáveis. O erro do pensamento burguês, em particular da sua ciência econômica (qualificada de forma procedente por Marx de vulgar), é magistral. Isso porque ela é incapaz de compreender o que é o capitalismo em termos de sua realidade essencial. Este pensamento alienado tampouco é capaz de saber para onde vão as sociedades capitalistas. O futuro será forjado pelas revoluções socialistas que colocaram um fim à dominação do capital? O capitalismo chegará a prolongar seus dias, tomando então a via da decadência da sociedade? O pensamento burguês ignora essa questão, presente no Manifesto.

De fato, lemos no Manifesto3, “[...] uma guerra que terminaria sempre em uma transformação revolucionária da sociedade ou por uma destruição das duas classes em luta" (MARX; ENGELS, 1995, p. 7).

Essa frase chamou-me a atenção há muito tempo.

É a partir dela que cheguei progressivamente a formular uma leitura do movimento histórico baseada no conceito de desenvolvimento desigual (a transformação é amenizada mais facilmente nas periferias de um sistema em vias de desenvolvimento do que nos centros) e nas formas de resposta ao desafio: a via revolucionária e a da decadência.

Portanto, escrevi as seguintes frases sobre este tema em Classe e Nação (Conclusão, Revolução ou decadência, em seguida):

Optando por derivar as leis do materialismo histórico da experiência universal, nos opomos à tese de um modo pré-capitalista único, o modo tributário, para o qual tendem todas as sociedades. Assim, a história do Ocidente - a construção romana, sua desagregação, a constituição da Europa feudal, enfim, a cristalização dos Estados absolutistas da época mercantilista - traduz, em suas particulariedades, a mesma tendência fundamental que se exprime para além da construção menos descontínua dos Estados tributários plenamente desenvolvidos - com a China constituindo a expressão mais representativa. Por um lado, em nossa tese, o modo escravista não possui um status universal tal como o modo tributário e o modo de produção capitalista. Ele é particular e aparece estreitamente relacionado à extensão das relações mercantis. Por outro lado, o modo feudal é uma forma primitiva, inacabada, do modo tributário.

A construção romana e, posteriormente, sua desagregação surgem nesta hipótese como uma tentativa de construção tributária demasiadamente precoce. O nível de desenvolvimento das forças produtivas não exigia uma centralização tributária na escala daquela do império romano. Portanto, essa primeira tentativa abortada seria seguida por uma passagem forçada pela fase de desintegração feudal, a partir da qual se reconstitui uma centralização nos marcos das monarquias absolutistas do Ocidente. Desse modo, somente o modo de produção no Ocidente se aproximará do modelo tributário finalizado. Além disso, é apenas a partir desse estágio que o nível de desenvolvimento das forças produtivas no Ocidente atingirão o nível do modelo tributário da China imperial, e essa coincidência não é fortuita.

3 A citação e todas as outras provém da edição da editora francesa Temps des Cerises, tradução de Laura Lafargue, 1995 .

Argum., Vitória, v. 10, n. 2, p. 17-28, maio/ago. 2018. 
O atraso do Ocidente, que se expressa pela derrocada romana e a dispersão do feudalismo, constitui definitivamente sua superioridade histórica. De fato, é a combinação específica de elementos do antigo modo tributário - com formas comunitárias bárbaras - que caracterizam o feudalismo e lhe confere sua flexibilidade. Isso dá conta da rapidez com que a Europa atravessa a fase tributária plenamenente desenvolvida, ultrapassando e compensando rapidamente o nível de desenvolvimento das forças produtivas do Oriente, de modo a desembocar no capitalismo. Esta flexibilidade e rapidez contrastam com a rigidez e a lentidão relativa na evolução dos modelos tributários do Oriente. O caso romano-ocidental não é, sem dúvida alguma, o único exemplo de aborto da construção tributária. Em condições específicas distintas, acreditamos ter recuperado pelo menos três outros casos típicos: o caso bizantinoárabe-otomano, o caso indiano e o caso mongol. A cada vez as tentativas de implementar sistemas de centralização tributária foram amplamente precedidas de exigências de desenvolvimento das forças produtivas para poderem se instalar duradouramente. Sem dúvida alguma as formas de centralização foram, em cada caso, combinações específicas distintas das estatais, para-feudais e mercantis. No Estado islâmico, por exemplo, é a centralização mercantil que teve um papel decisivo; os fracassos sucessivos se relacionam com o conteúdo hinduísta, que se opôs ao confuncionismo; em relação à centralização do império de Gengis Khan, como sabemos, ela foi de duração muito curta.

O sistema imperialista contemporâneo é, também, um sistema de centralização do excedente em escala mundial. Esta centralização opera sobre a base de leis fundamentais do modo capitalista e em condições de domínio dos modos pré-capitalistas da periferia submissa. Formulamos a lei de acumulação do capital em escala mundial como forma de expressão da lei do valor operando nessa escala. O sistema imperialista de centralização do valor se caracteriza pela aceleração da acumulação e do desenvolvimento das forças produtivas no centro do sistema, enquanto que em sua periferia esses processos são defasados e deformados. Desenvolvimento e subdesenvolvimento são o verso e o reverso de uma mesma moeda. Compreende-se então que o desenvolvimento e o sub-desenvolvimento posterior das forças produtivas na periferia devem passar pela dissolução do sistema imperialista de centralização do excedente. Uma fase necessária de descentralização, 'a construção da transição socialista nacional, deve preceder a reunificação em um nível mais elevado de desenvolvimento, que constituirá a sociedade planetária sem classes'.

São os homens que fazem sua história... O conceito de praxis é próprio da sociedade, como expressão da síntese do determinismo e da intervenção humana. A relação dialética infra-estrutura/super-estrutura lhe é igualmente própria e não tem correspondente na natureza. Essa relação não é uni-lateral: a super-estrutura não é o reflexo de exigências da infra-estrutura. Se de fato fosse isto, a sociedade seria sempre alienada e não vemos como poderia chegar a se libertar.

É por isto que propomos distinguir dois tipos qualitativamente diferentes de transição de um modo a outro. Quando a passagem se faz no inconsciente, ou pela consciência alienada, quer dizer quando a ideologia que atua sobre as classes não permite o controle do processo de mudança, essa passagem aparece como efeito operado de forma análoga a uma mudança natural, com a ideologia sendo parte dessa natureza. Para esse tipo de passagem reservamos a expressão modelo decadente. Em contraposição, se a ideologia chega a alcançar a dimensão total e real da mudança desejada, e tão somente assim, pode-se falar de revolução (AMIN, 1980, p. 238).

O pensamento burguês tem de ignorar a questão para pensar o capitalismo como um sistema racional para todos os tempos vindouros, para pensar o fim da história.

Argum., Vitória, v. 10, n. 2, p. 17-28, maio/ago. 2018. 
2.

Marx e Engels, pelo contrário, enfatizam bem - desde a epóca do Manifesto - que o capitalismo não passa de um breve parentêses na história da humanidade. No entanto, o modo de produção capitalista ainda mal ultrapassara as fronteiras da Inglaterra, da Bélgica e de uma pequena região do norte da França e do oeste prussiano. Nada de comparável em todo o restante da Europa.

Claro que Marx não sabia bem em qual país se iniciaria a revolução. A Inglaterra, o único país já avançado no capitalismo? Não. Marx pensava que isto só seria possível se o proletariado inglês se libertasse de seu alinhamento em relação ao apoio à colonização da Irlanda. A França, país menos avançado no plano de seu desenvolvimento capitalista, porém avançado no plano de maturidade política de seu povo, legado de sua grande revolução? Talvez. A Comuna de 1871 confirmou sua intuição. Pela mesma razão Engels esperava pouco da Alemanha atrasada: a revolução proletária e a revolução burguesa poderiam colidir uma com outra. Neste sentido, O Manifesto expressa esse ponto da seguinte forma:

\footnotetext{
É principalmente para a Alemanha que se volta a atenção dos comunistas, por conta de que a Alemanha se encontra às vésperas de uma revolução burguesa, e porque terminará essa revolução em condições mais avançadas na civilização européia e com um proletariado infinitamente mais desenvolvido do que a Inglaterra e a França possuiam no século XVIII. Por conseguinte a revolução burguesa alemã seria apenas o prelúdio de uma revolução proletária (MARX; ENGELS, 1995, p. 54).
}

Isso não ocorreu: a unificação sob o bastão da Prússia reacionária, a mediocridade política dos burgueses alemães e sua covardia possibilitaram que o nacionalismo triunfasse e marginalizasse a revolta popular. Marx, no fim de sua vida, volta seu olhar para a Rússia, que ele espera que se engage na via revolucionária, como comprova sua correspondência com Vera Zassoulitch.

Portanto, Marx teve bem clara a intuição de que a transformação revolucionária poderia ser iniciada a partir da periferia do sistema - os elos fracos na linguagem posterior de Lénin. No entanto, Marx não tirou em sua época todas as conclusões que se impunham. Foi necessário que a história avançasse no século XX para os comunistas, com Lénin e Mao, serem capazes de imaginar uma nova estratégia qualificada como a construção do socialismo em um único país. Uma expressão inapropriada para a qual prefiro a extensa redundância: os avanços desiguais na extensa estrada da transição socialista, localizados em regiões onde a estratégia do imperialismo dominante combate e isola.

O debate relacionado ao problema relativo à longa transição histórica socialista e o alcance universal desse movimento revela uma série de questões da classe em si à classe para si; as formas e efeitos da mundialização capitalista; o lugar dos camponeses nessa longa transição; e a diversidade das expressões do pensamento anti-capitalista, questões que abordo nos ítens seguintes.

3.

Marx, mais do que ninguém, compreendera que o capitalismo tinha vocação para conquistar o mundo. Ele escreve numa época em que o capitalismo ainda estava longe de ter atingido

Argum., Vitória, v. 10, n. 2, p. 17-28, maio/ago. 2018. 
sua complitude e retoma de suas origens esta vocação, a descoberta da América que inaugura a transição de três séculos mercantilistas para o capitalismo plenamente desenvolvido. Ele escreve no Manifesto, que "[...] a grande indústria criou o mercado mundial, preparado pela descoberta da América”, [...] "[...] pela exploração do mercado mundial, a burguesia dá um caráter cosmopolita ao consumo de todos os países” (MARX; ENGELS, 1995, p. 11).

Marx se alegra com esta mundialização, fenômeno novo na história da humanidade, conforme se observa em diversas passagens do Manifesto. Por exemplo, "[...] onde quer que tenha conquistado o poder, ela (leia-se a burguesia) menospreza as relações feudais patriarcais e idílicas [...]" (MARX; ENGELS, 1995, p. 10). E

[...] a burguesia submeteu o campo à cidade... e, desse modo, preservou uma grande parte da população do endurecimento da vida no campo... da mesma forma que ela subordinou as regiões rurais às cidades, as nações bárbaras e semi-civilizadas às nações civilizadas, ela subordinou os países agrícolas aos países industrializados, o Oriente ao Ocidente [...] (MARX; ENGELS, 1995, p. 13).

As coisas estão claras: Marx jamais foi um saudosista, lamentando os velhos bons tempos. Ele sempre expressou pontos de vista modernistas, a ponto de parecer um euro-cêntrico.

Ele foi muito além neste aspecto. O trabalho rural, cada vez mais bruto, não foi substituído por um trabalho urbano de proletários tão duro quanto? Além disso, Marx não ignora a miséria urbana que acompanhou a expansão capitalista. Ele foi bem profundo a esse respeito.

O Marx do Manifesto teria mensurado bem as consequências políticas da destruição do campesinos, na própria Europa e, a fortiori, nos países colonizados? Retomarei essas questões estreitamente relacionadas com o caráter desigual do desenrolar mundial do capitalismo.

Marx e Engels, no Manifesto, ainda ignoravam que o desenrolar mundializado do capitalismo não é aquele que imaginavam, homogeneizante. Isto é, concedendo ao Oriente conquistado sua oportunidade, permitindo-lhe sair do impasse que sua história lhe encerrara, tornando-o, tal qual os países do Ocidente, nações civilizadas, isto é, industriais. Alguns textos posteriores de Marx tratam da colonização da Índia conforme essa interpretação.

Contudo, Marx mudou de opinião em seguida. Suas alusões comprovam isto, mais do que o desenvolvimento argumentativo sistemático sobre os efeitos destruidores apresentados sobre a conquista colonial. Marx gradualmente toma consciência do que eu denomino desenvolvimento desigual: a construção sistemática do contraste centro dominante/periferias dominadas e, por isso mesmo, a impossibilidade de recuperar-se no contexto da mundialização capitalista, imperialista por natureza e dado os instrumentos do capitalismo.

E isso dado que, se fosse possível recuperar-se no processo de mundialização capitalista, força política, social e ideológica alguma poderia se opor a esse processo com sucesso.

O Marx do Manifesto ainda pensava que a abertura comercial ocorrera na China. O Manifesto coloca isso nos seguintes termos, que: "[...] o preço baixo de seus produtos é a artilharia pesada que derruba todas as muralhas da China e faz com que os bárbaros mais obstinada-

Argum., Vitória, v. 10, n. 2, p. 17-28, maio/ago. 2018. 
mente hostis aos estrangeiros capitulem" (MARX; ENGELS, 1995, p. 12). Sabemos que não foi assim: foram os canhões da marinha britânica que se sobrepusseram contra a concorrência dos produtos chineses. Sabemos que não foi porque sua indústria estava mais avançada que a Inglaterra dominou a Índia; ao contrário, foi o domínio sobre a Índia que permitiu que a Inglaterra assumisse a posição hegemônica no sistema capitalista do século XIX.

No entanto, o Marx mais maduro soube deixar o eurocentrismo de sua juventude. Marx sabia mudar de opinião à luz da evolução do mundo.

Portanto, em 1848 Marx e Engels consideravam que a probabilidade de uma ou diversas revoluções socialistas era grande na Europa daquela época. Desse modo, confirmavam que o capitalismo é apenas um breve parênteses na história. Os fatos rapidamente lhes deram razão. No entanto se a Comuna de Paris (1871) foi a primeira revolução socialista, ela também foi a última manifestação em um país capitalista desenvolvido. Com a formação da segunda Internacional, Engels não perde a esperança de um novo avanço revolucionário, particularmente na Alemanha. A história lhe desmentiu. No entanto a traição da Segunda Internacional em 1914 não foi surpresa. Para além da deriva reformista, naquele momento o alinhamento dos partidos operários em toda a Europa em relação à expansão imperialista e colonialista das burguesias mostravam que não se tinha muita coisa a esperar dos partidos da Segunda Internacional.

A linha de frente da transformação do mundo iria deslocar-se para o Leste, na Russia em 1917 e depois na China. Marx certamente não havia previsto isto, porém seus escritos posteriores deixam entender que provavelmente não ficaria surpreso, pelo menos no que diz respeito à Rússia.

Por outro lado, Marx pensava, no que diz respeito à China, tratar-se de uma revolução burguesa que estava na ordem do dia. No dia seguinte à intervenção das potências europeias em resposta à revolta dos Boxers, ele lembra que na próxima vez que os exércitos europeus tentarem entrar na China serão surpreendidos com um painel avisando atenção, estão entrando na República burguesa da China!. O Kuo Min Tang da revolução de 1911, aquele de Sun Yat Sen, tinha proclamado a República (burguesa), como Marx previra. No entanto, isso não foi suficiente para vencer as forças do antigo regime em que os senhores da guerra reconquistaram terreno, nem para fazer recuar o domínio das potências imperialistas, o Japão em particular. O fracasso do KMT de Tchang Kai-chek respaldava o ponto de vista de Lenin e de Mao: não havia mais espaço para revoluções burguesas autênticas, esta época seria aquela das revoluções socialistas. Tal como o Fevereiro russo de 1917 não tinha futuro, incapaz de triunfar sobre o antigo regime, impõe-se Outubro, a revolução chinesa de 1911 denominada como a dos comunistas maoistas, únicos capazes de responder às expectativas de liberação, tanto nacional quanto social.

Portanto, a Rússia é o elo fraco do sistema, que inicia a segunda revolução socialista. No entanto, esta não é apoiada, mas sim combatida pelo movimento operário europeu. Rosa Luxemburg utiliza termos violentos neste momento de deriva dos movimentos sociais euro- 
peus. Ela fala de "[...] carência [...]", de “[...] incapacidade do proletário alemão assumir sua missão histórica [...]", de “[...] traição [...]"4.

Da minha parte, propus uma análise desse recuo histórico das classes trabalhadoras do Ocidente desenvolvido, deixando de lado suas tradições revolucionárias do século XX, de modo a acentuar os efeitos devastadores do caráter imperialista da expansão mundial do capitalismo e dos benefícios que as sociedades envolvidas obtém (e não somente suas burguesias); benefícios estes decorrentes de sua posição dominante. Portanto, considerei necessário, numa leitura da contribuição da Revolução de Outubro de 1917, consagrar um capítulo inteiro (o capítulo dois de meu livro Le centenaire de la Révolution d'Octobre 1917, intitulado Révolutions et contre-révolutions de 1917 à 2107) (AMIN, 2017a) à análise dos desenvolvimentos que conduziram as classes européias a renunciar sua missão histórica, retomando os termos de Rosa Luxemburg.

\section{4 .}

Desse modo, os avanços revolucionários na longa estrada da transição socialista para o comunismo vão se consolidar apenas nas sociedades da periferia do sistema mundial, precisamente nos países onde um segmento pioneiro compreendera que não era possível se recuperar por meio da inserção na mundialização capitalista, consequentemente seria necessário fazer outra coisa. Isto é, avançar para uma transição de natureza socialista. Lénin e Mao expressaram essa convicção ao proclamarem que nossa época não é mais aquela das revoluções burguesas, mas que doravante é aquela das revoluções socialistas.

Essa conclusão implica uma outra: as transições socialistas se consolidarão necessariamente em um só país que, além disso, permanecerá fatalmente isolado pelo contra-ataque do imperialismo mundial. Não há alternativa; não haverá revolução mundial. Contudo, as nações e os Estados engajados nesta via serão então confrontados a um duplo desafio: responder à guerra permanente (fria ou quente) conduzida pelas potências imperialistas; e associar as maiorias camponesas com os avanços no novo caminho do socialismo. Portanto, nem o Manifesto, nem mesmo Marx e Engels estavam em condições de dizer alguma coisa a esse respeito. Caberia ao marxismo em vigor substituí-los.

Estas reflexões me conduzem a colocar no seu devido lugar as considerações sobre os camponeses, desenvolvidas por Marx e Engels no Manifesto.

Marx coloca-se em sua época, que é ainda aquela da revolução burguesa inacabada até mesmo na Europa. A esse respeito lê-se no Manifesto, que: "[...] durante esta fase os proletários não combatem ainda seus próprios inimigos, porém os inimigos de seus inimigos, isto é, os restos da monarquia absolutista, os proprietários fundiários... toda vitória conquistada nestas condições é uma vitória da burguesia” (MARX; ENGELS, 1995, p. 18).

Quando a revolução burguesa dá a terra aos camponeses - caso particular da França - o campesinato, em sua maior parte, coloca-se então no campo dos defensores do caráter sagrado da propriedade privada, tornando-se adversário do proletariado.

\footnotetext{
4 Ver Rosa Luxemburg. La révolution russe. Paris: ed l’Aube, 2017. p. 10 e 59.
} 
No entanto, a transferência do centro de gravidade da transformação socialista no mundo, migrando dos centros imperialistas dominantes para as periferias dominadas, modifica radicalmente a questão campesina. Os avanços revolucionários só são possíveis em sociedades mantidas ainda sob condições amplamente rurais se as vanguardas socialistas forem capazes de colocar em prática estratégias que integrem a maioria do campesinato no campo de combate contra o capitalismo imperialista.

\section{5 .}

Marx e Engels jamais acreditaram, quando redigiram o Manifesto e mesmo posteriormente, na vocação revolucionária espotânea do proletariado. Isso porque "[...] as ideias dominantes sempre foram as ideias da classe dominante" (MARX; ENGELS, 1995, p. 34). Por isso os trabalhadores aderem à ideologia da concorrência, pedra angular do funcionamento da sociedades capitalista. Consequentemente, "[...] a organização do proletário em classe, e em seguida em partido político, é incessantemente destruída pela concorrência que os operários produzem entre si” (MARX ; ENGELS, 1995, p. 20).

A transformação do proletário em classe em si à classe para si implica intervenção ativa de uma vanguarda comunista :

[...] portanto os comunistas praticamente são o segmento mais resoluto, os mais avançados de cada país, o segmento que estimula os demais; teoricamente eles têm a vantagem sobre o resto do proletariado de uma inteligência livre de condicionalidades, da trajetória e dos fins gerais do movimento operário (MARX, ENGELS, 1995, p. 25).

A afirmação do papel inevitável da vanguarda não é em Marx um pedido a favor de um partido único. Lemos no Manifesto, que: "Os comunistas não formam um partido em oposição aos outros partidos operários... Eles não proclamam princípios sectários sobre os quais gostariam de modelar o movimento operário" (MARX; ENGELS, 1995, p. 25).

Em seguida continua com sua concepção do que deveria ser uma Internacional proletária. Marx julgava necessário integrar todos os partidos e correntes de pensamento e de ação que desfrutassem de um apoio popular e operário real. A primeira Internacional contava dentre suas fileiras com os blanquistes franceses, os lassaliens alemães, os trade-unionista ingleses, os prudonianos, os anarquistas bakunianos. Marx não amenizou suas críticas, frequentemente mordazes, com respeito a muitos de seus corregionários. E diríamos talvez que a violência desses debates conflituosos está na origem da brevidade da existência dessa Internacional. Que seja! Essa organização pelo menos foi a primeira escola de formação dos quadros posteriormente engajados no combate contra o capitalismo... Duas observações ligadas à questão do papel do partido e dos comunistas:

A primeira diz respeito à relação entre o movimento comunista e a nação. Lê-se no Manifesto, que:

Os operários não têm pátria. Não podemos nos orgulhar de que eles não a tenham. Como o proletariado de cada país deve, em primeiro lugar, conquistar o poder político, se constituir em classe essencial à nação, ele ainda é nacional, embora de forma alguma no sentido burguês, [...] a luta do proletariado contra a burguesia, embora não seja no fundo uma luta nacional, se reveste sob essa forma (MARX; ENGELS, 1995, p. 33).

Argum., Vitória, v. 10, n. 2, p. 17-28, maio/ago. 2018. 
No mundo capitalista os proletários não têm pátria porque neste mundo, a única função do nacionalismo é, por um lado, dar legitimidade à exploração dos trabalhadores do país em questão e, por outro lado, legitimar o combate da burguesia contra seus concorrentes estrangeiros e a suas ambições de expansão imperialista.

No entanto, tudo se altera com o eventual triunfo de uma revolução socialista. O que mencionei acima sobre o início da transição socialista nas sociedades periféricas e a respeito da diversidade necessária das vias empreendidas, tal como aquela cujo objetivo final, desejável do comunismo, reforça a tendência do caráter nacional das classes trabalhadoras.

Portanto, citarei a esse respeito o que escrevi em La souveraineté au service des peuples ${ }^{5}$, (páginas 4 e seguintes):

O apoio ou oposição à soberania nacional constituem objeto de sérios mal entendidos, enquanto o conteúdo de classe na estratégia em que estão inseridos não seja identificado. O bloco social dominante nas sociedades capitalistas sempre concebe a soberania nacional como um instrumento para promover seus interesses de classe, a saber: internamente a exploração capitalista do trabalho e, simultaneamente, a consolidação de sua posição no sistema mundial. Atualmente, no contexto de um sistema liberal mundializado e dominado pelos monopólios financiarizados da tríade (EUA, Europa, Japão), a soberania nacional constitui o instrumento que permite às classes dirigentes manter suas posições competitivas no seio do sistema. O governo dos Estados Unidos oferece o exemplo mais claro dessa prática permanente: neste caso a soberania é concebida como domínio exclusivo do capital monopolístico estado-unidense e, com este objetivo, concebe-se primazia do direito nacional dos Estados Unidos sobre o direito internacional. No passado esta era também a prática das potências imperialistas europeias e os principais Estados europeus continuam a praticá-lo no interior da União europeia ${ }^{6}$.

Compreende-se agora porque o discurso nacional, elogiando as virtudes da soberania e escondendo os interesses de classe a que ela serve, sempre foi inaceitável para aqueles que defendem as classes trabalhadoras. Contudo, não devemos reduzir a defesa da soberania a essa modalidade, a do nacionalismo burguês. Esta defesa é também decisiva para a proteção de uma alternativa popular inserida no longo caminho para o socialismo. Ela constitui até uma condição incontornável de avanço nessa direção. A razão disto é que a ordem mundial (tanto quanto sua sub-ordem europeia) nunca será transformada por cima, por decisões coletivas das classes dominantes. Neste sentido, o progresso é sempre resultado de avanços desiguais das lutas de um país com outro. A transformação do sistema mundial (ou do sub-sistema europeu) é produto de mudanças que se impõem no contexto dos diferentes Estados, com o progresso modificando as relações de força internacionais entre esses Estados. O Estado nacional subsiste como a única instância onde as lutas decisivas se desenrolam, e que, afinal de contas, transformam o mundo.

Os povos das periferias desse sistema, polarizado por natureza, possuem uma longa experiência desse nacionalismo positivo e progressista, representado pelo antiimperialismo. Esse rejeita a ordem mundial imposta pelos centros, sendo portanto potencialmente anticapitalista. Digo apenas potencialmente, pois o nacionalismo pode ser igualmente portador de uma ilusão da possibilidade de construir um capitalismo nacional que chegue a recuperar as construções nacionais dos centros dominantes. $\mathrm{O}$ nacionalismo nas periferias só é progressista sob essa condição, de manter-se anti-imperialista. Isto é, entrar em confronto com a ordem liberal mundializa-

5 A soberania nacional a serviço dos povos.

${ }^{6}$ Discuti essa questão específica da Europa em L’implosion du capitalisme contemporain, capítulo 4.

Argum., Vitória, v. 10, n. 2, p. 17-28, maio/ago. 2018. 
da. Qualquer outro nacionalismo que aceite a ordem liberal mundial (neste caso sendo apenas de fachada) é apenas um instrumento das classes dirigentes locais, ansiosas para participar da exploração de seu povo. Ou então, no máximo, participando da exploração de outros participantes mais débeis, agindo como poderes subimperialistas.

A confusão entre esses dois conceitos contraditórios de soberania nacional e, por conseguinte, a recusa de todo nacionalismo destrói qualquer possibilidade de deixar a ordem liberal mundial. Infelizmente, a esquerda na Europa - e alhures - frequentemente fazem essa confusão (AMIN, 2017b, p. 4).

A segunda observação a fazer diz respeito à segmentação das classes trabalhadoras, em detrimento da simplificação da sociedade associada ao avanço do capitalismo, tal como se verifica no Manifesto "[...] contudo, o caráter distintivo de nossa época é o de ter simplificado os antagonismos de classe. A sociedade divide-se cada vez mais em dois vastos campos, em duas classes inimigas: a burguesia e o proletariado" (MARX; ENGELS, 1995, p. 7).

Este duplo movimento - de generalização da condição proletária e simultaneamente de segmentação do mundo do trabalho - hoje em dia é bem mais visível do que era em 1848, quando ele apenas se configurava.

Assistimos ao longo do século XX, prolongando-se até hoje, a uma generalização sem precedentes da condição proletária. Atualmente nos centros, a quase totalidade da população está reduzida ao status de assalariados vendedores de sua força de trabalho. Nas periferias os camponeses são integrados, como nunca haviam sido, nas redes comerciais que aniquilaram seu status de produtores independentes, para torná-los sub-contratados dominados, reduzidos de fato ao status de vendedores de sua força de trabalho.

Além disso, esse movimento é crescentemente associado ao de pauperização. "O trabalhador cai na pauperização e esta cresce mais rapidamente do que a população e a riqueza" (MARX ; ENGELS, 1995, p. 23). Essa tese de pauperização, retomada e amplificada em $\mathrm{O} \mathrm{Ca}$ pital, foi objeto de críticas sarcásticas dos economistas vulgares. No entanto, na escala do sistema capitalista mundial, ela é a única que dá sentido pleno à análise da realidade. A pauperização em questão é consideravelmente mais visível do que Marx imaginara.

Contudo, e paralelamente, os poderes capitalistas chegaram a enfraquecer o perigo que a proletarização generalizada representava através de estratégias sistemáticas de segmentação do mundo do trabalho, do nível nacional ao internacional.

6.

A sessão III do Manifesto, intitulado Literatura socialista e comunista, poderia parecer a um leitor contemporâneo como verdadeiramente pertecente ao passado.

De fato, Marx e Engels nos oferecem comentários relativos a temas e textos que pertecem à época deles. Ultrapassados, esquecidos, esses temas são desde então somente objeto de arquivistas do passado.

Argum., Vitória, v. 10, n. 2, p. 17-28, maio/ago. 2018. 
No entanto, sofri um impacto por conta de analogias persistentes dos movimentos sociais com discursos de outrora, ou mesmo contemporâneos. Marx denuncia os reformistas de todos os tipos, que nada compreeenderam da lógica resultante do capitalismo. Teriam eles desaparecidos da cena? Marx denuncia os mentirosos que denunciam os mal-feitos do capitalismo, porém, como o Manifesto diz que; “[...] na luta política, eles tomam como parte acabada todas as medidas violentas contra a classe operária” (MARX; ENGELS, 1995, p. 39). Os facistas do século XX e de hoje, os movimentos saudosistas pretensamente religiosos (Os irmãos mulçulmanos, os fanáticos do Induismo ou do Budismo) são diferentes?

Considerá-los como críticos dos rivais do marxismo, de suas ideologias e dos meios sociais dos quais são os porta-vozes não implica, nem em Marx, nem para nós, que o movimento anti-capitalista autêntico seja necessariamente diverso em suas fontes de inspiração. A esse respeito, remeto o leitor ao que escrevi recentemente, na perspectiva de reconstrução de uma Internacional, condição para a eficácia das lutas e de sua vocação para reconstruir uma visão internacionalista do futuro. Ref: Unidade e diversidade dos movimentos populares do socialismo; em, Egypte, nassérisme et communisme: unité et diversité des socialismes 7; publicado pela les Indes Savantes, em 2014; Nota não publicada, na edição de 2017, "A reconstrução indispensável da Internacional dos trabalhadores e dos povos"8 (AMIN, 2014).

\section{7 .}

Concluirei com palavras sobre minha leitura do Manifesto: O Manifesto é, por um lado, um hino à glória da modernidade capitalista, do dinamismo que ela inspira, sem nada semelhante na longa história da civilização. No entanto, ele é, ao mesmo tempo, o canto dos cisnes desse sistema, cujo próprio movimento não é mais do que o de gerar o caos, como Marx sempre compreendeu e alertou. A razão histórica do capitalismo não é nada mais do que aquela de ter reunido em um tempo curto todas as condições materiais, políticas, ideológicas e morais que impõem sua superação.

Sempre partilhei desse ponto de vista que acredito ser o de Marx, desde o Manifesto até o início da Segunda internacional, vivenciada por Engels. As análises que propus, relacionadas à longa maturação do capitalismo - 10 séculos - e as contribuições de diferentes regiões do mundo para essa maturação (China, Oriente islâmico, cidades italianas e, enfim, a Europa Atlântica); o curto apogeu (o século XIX) e, enfim, seu longo declínio manifestado pelas duas crises sistêmicas (a primeira de 1890 à 1945, a segunda a partir de 1975 até os dias de hoje) têm a ambição de aprofundar o que em Marx era apenas uma intuição (AMIN, 2012).

Essa interpretação do lugar do capitalismo na história foi abandonada pelas correntes reformistas no seio do marxismo da Segunda Internacional e, posteriormente, também para além do marxismo. Ela foi substituída por uma visão segundo a qual o capitalismo só teria cumprido sua função quando chegasse a homogeinizar o Planeta de acordo com o modelo dos centros europeus. Persistindo-se neste caminho sem saída, pois o desenvolvimento mundializado do capitalismo é por natureza polarizador, substituiremos a transformação do mundo através da via revolucionária pela submissão aos reveses fatais subjacentes à decadência da civilização.

\footnotetext{
7 Egito, nazismo e comunismo: unidade e diversidade de socialismos.

${ }^{8}$ L'indispensable reconstruction de l'Internationale des travailleurs et des peuples (AMIN, 2014).
}

Argum., Vitória, v. 10, n. 2, p. 17-28, maio/ago. 2018. 


\section{Referências}

AMIN, Samir. Le centenaire de la révolution d'octobre 1917. Paris: Editions Delga, $2017 a$.

AMIN, Samir. La souverainete au service des peuples: l'agriculture paysanne, la voie de l'avenir. Genève: Cetim, 2017b.

AMIN, Samir. L'implosion du capitalisme contemporain. Paris: Editions Delga, 2012.

AMIN, Samir. Class and nation, historically and in the current crisis. London: Monthly Review, 1980.

MARX, K.; ENGELS, F. Le manifeste du Parti Communiste. Traduit par Laura Lafargue. Paris: Le Temps des Cerises, 1995.

LUXEMBURGO, Rosa. La révolution russe. Paris: Ed l'Aube, 2017.

\footnotetext{
Samir AMIN († In memorian)

Economista egípcio. Especializado em questões do Terceiro Mundo, ele desenvolveu o conceito centro-periferia como uma explicação global das relações econômicas entre os países do capitalismo avançado e subdesenvolvido, focalizando em particular a África negra. Sua principal proposta, juntamente com a de outros economistas do Terceiro Mundo, apoiou a necessidade de os países periféricos passarem a uma desconexão do mercado mundial e evitarem participar da divisão internacional do trabalho para enfrentar o subdesenvolvimento. Notável entre suas obras La acumulación a escala mundial (1970), El desarrollo desigual (1973), La nación árabe (1976) y La desconexión (1986). Além de ser um dos impulsores do Fórum Social Mundial.
} 